\title{
Undifferentiated Embryonal Sarcoma of the Liver in Adults
}

\author{
Jingyang Huang \\ Department of Pathology and Laboratory Medicine, University of Alberta, \\ Edmonton, Canada
}

Author for Correspondence: Jingyang Huang, Department of Pathology and Laboratory Medicine, University of Alberta, Edmonton, Canada.

E-mail: Jingyang.Huang@albertaprecisionlabs.ca

Doi: https://doi.org/10.36255/exonpublications.livercancer.2021.ch9

\begin{abstract}
Undifferentiated embryonal sarcoma of the liver (UESL) is an aggressive malignancy that most commonly affects the pediatric age group. This tumor very rarely occurs in adults and, in such instances, can pose a considerable diagnostic challenge for the clinicians, radiologists, and pathologists involved. The clinical presentation is most often non-specific, and the radiology shows a solid and cystic liver mass which has a considerable differential on imaging. Especially in adult patients, UESL is a diagnosis of exclusion meaning that all other diagnostic possibilities must be excluded before the diagnosis of UESL can be confidently made. From a pathology perspective, this means careful examination of the histology along with a comprehensive panel of immunohistochemistry for almost all cases of newly diagnosed UESL. The prognosis of UESL used to be dismal, but with advances in treatment and the introduction of a multimodality approach, there has been considerable progress in improving outcomes and survival for patients with this aggressive tumor. This chapter outlines the clinical, radiological, and pathological features of UESL. An in-depth discussion is undertaken to describe the diagnostic approach and the differential diagnosis for this rare and challenging tumor.
\end{abstract}

Keywords: diagnosis of exclusion; liver tumor; pediatric liver sarcoma; rare adult hepatic sarcoma; undifferentiated embryonal sarcoma of the liver

In: Liver Cancer. Sergi CM. (Editor). Exon Publications, Brisbane, Australia. ISBN: 978-0-6450017-2-3; Doi: https://doi.org/10.36255/exonpublications.livercancer.2021

Copyright: The Authors.

License: This open access article is licenced under Creative Commons Attribution-NonCommercial 4.0 International (CC BY-NC 4.0) https://creativecommons.org/licenses/by-nc/4.0/ 


\section{INTRODUCTION}

Undifferentiated embryonal sarcoma of the liver (UESL) is a rare hepatic mesenchymal tumor that occurs predominately in children $(1,2)$. This tumor is most common between the ages of 6 and 10 (1). It is an aggressive tumor that has significant metastatic potential. Around 60 cases have been reported in adults since this pediatric tumor was first described. The average age for these adult cases was 24 years and the oldest was 84 years of age (3). Because of the limited tissue encountered on biopsy specimens of adult patients, undifferentiated embryonal sarcomas can pose a considerable diagnostic conundrum. Extensive immunohistochemical work-up along with correlation with all available clinical and radiological findings is usually required before a firm diagnosis of UESL can be made. The diagnosis of an undifferentiated embryonal sarcoma is best considered a diagnosis of exclusion in adult patients since the primary purpose of ancillary testing is to exclude all other possibilities (4-6). Timely detection and surgical resection along with neoadjuvant therapy are essential in achieving favorable outcomes $(1,2)$. In pediatric patients, the 5 -year survival is around $86 \%$, with surgical resection being the most important aspect of treatment $(1,3)$.

\section{CLINICAL PRESENTATION}

UESL is a rare liver mesenchymal neoplasm that most often occurs in children between 6 and 10 years of age (1). UESL is the third most common primary liver malignancy in children after hepatoblastoma and hepatocellular carcinoma $(1,7)$. This tumor has been reported in adults, but these cases are exceptionally rare (3). UESL most commonly occurs in the right lobe of the liver with many patients being asymptomatic for considerable periods of time (3). Those patients who are symptomatic may present with non-specific features such as nausea, vomiting, weight loss, fever, and abdominal pain and distention $(1,2)$. Serology in most patients is usually negative but in a minority of cases, elevated liver enzymes, alpha fetoprotein, and erythrocyte sedimentation rates have been encountered $(1,2)$.

\section{RADIOLOGY}

Imaging will demonstrate a heterogeneous liver mass with solid and cystic areas (8). There are usually no specific imaging features that can help suggest an undifferentiated embryonal sarcoma (2). On ultrasound, the tumor may appear more solid than cystic because of its high water content (7). On CT, UESL will be a hypodense solid and cystic mass (Figure 1A) (2). On MRI, the cysts within the mass may show multiple fluid-fluid levels (FigurelB) (9). Due to their cystic character radiologically, UESLs have been known to be mistaken for benign cystic entities such as biliary cystadenomas, hydatid cyst disease, or venolymphatic malformations $(2,8,9)$. In fact, the radiological appearance of USEL can be quite misleading to a point where delays in diagnosis or even the initiation of the wrong treatment have occurred $(4,10)$. 

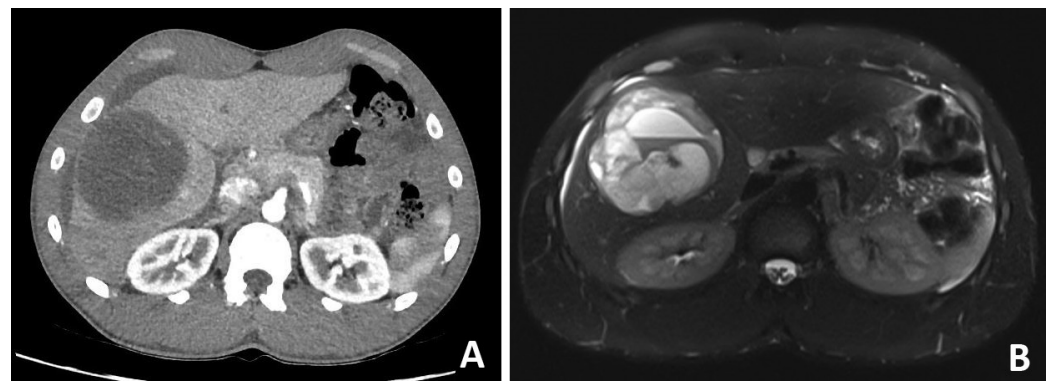

Figure 1. Radiology of undifferentiated embryonal sarcoma of the liver (UESL). A. An arterial phase contrast-enhanced computed tomography from a young adult male with UESL. It demonstrates a large hypodense mass in the right lobe of the liver. B. Magnetic resonance image showing a large mass in right lobe of the liver with heterogenous and cystic features along with fluid-fluid levels.

\section{GROSS FEATURES}

Hepatic resection specimens show masses most commonly located in the right lobe of the liver. Many of these tumors are quite large by the time surgical intervention is undertaken. The tumor commonly has a pseudocapsule and due to its large size, compresses the adjacent normal liver parenchyma. The tumor itself has a variegated appearance showing cystic and solid areas that have gelatinous, hemorrhagic, and/or necrotic features (Figure 2) $(2,3,7)$. Tumors that have been large enough to rupture through the liver capsule have also been encountered (11-13).

\section{HISTOLOGY}

USEL is made of high-grade undifferentiated cells with varying degrees of spindling and myxoid change. Like its gross appearance, this tumor is commonly heterogeneous histologically, and the morphology will vary considerably depending on the area of examination. Some areas may appear to be composed of a relatively uniform sheet of undifferentiated cells while other areas demonstrate wildly pleomorphic anaplastic cells, some with multinucleation and a myxosarcomatous background (Figure 3A). Due to its high-grade nature, considerable areas of necrosis are found in the majority of cases and abundant mitoses are easily identified (Figures 3B) $(2-4,6,7,14)$. Areas of cystic change can often be seen histologically (Figure 3C), which corresponds to this tumor's cystic appearance on both gross and radiology. Despite the presence of a pseudocapsule, cords of normal hepatocytes and bile ducts are commonly entrapped along the periphery of this tumor (Figure 3D) (2). Periodic acid-Schiff positive diastase (PASD)-resistant eosinophilic globules are often seen in the tumor stroma or within the cytoplasm of some of the tumor cells (Figures 3E and F) $(2,3,6)$. Around half of UESLs will have areas of extramedullary hematopoiesis (14) and an extremely rare case with osteoid formation has been reported (13). 


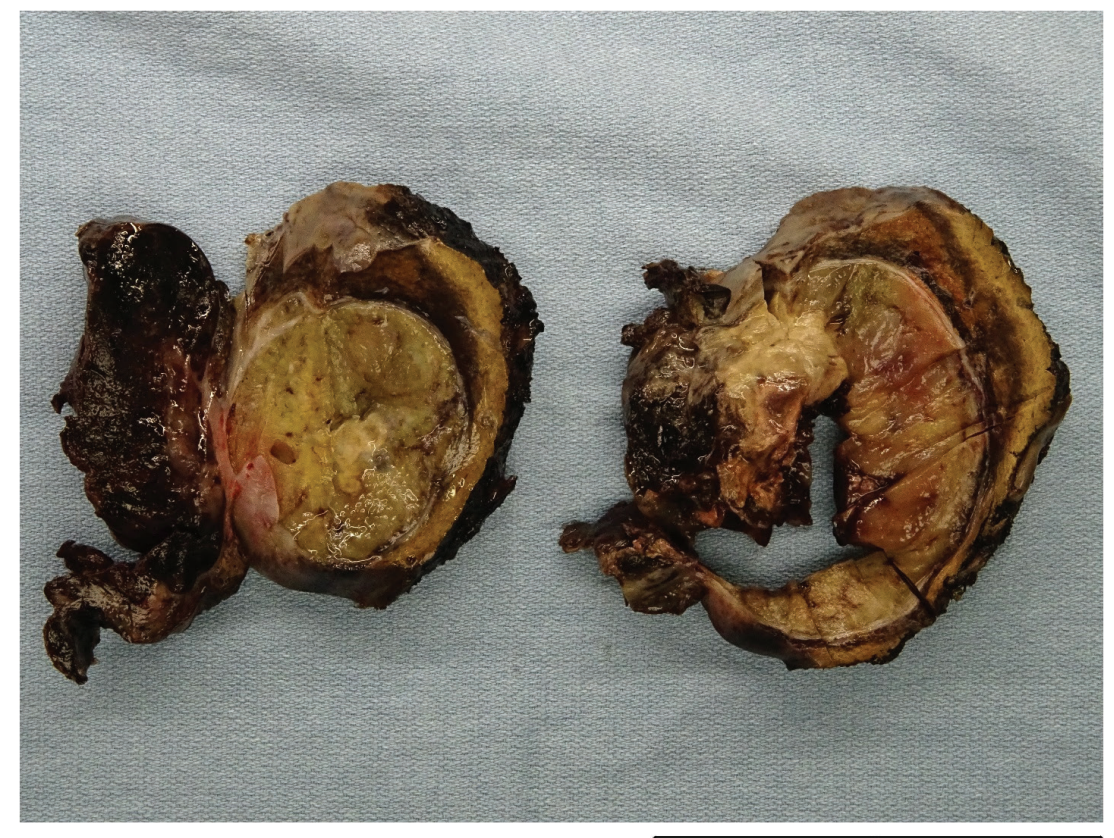

Figure 2. Gross features of undifferentiated embryonal sarcoma of the liver (USEL). This gross photograph of a UESL shows a variegated gelatinous liver mass with a lobulated architecture and areas of necrosis and hemorrhage. This case also shows the tumor rupturing through the capsule of the liver.

\section{IMMUNOHISTOCHEMISTRY}

There is no immunohistochemistry that is specific for UESL. In fact, the key role of immunohistochemistry is to rule out other possible tumors in the differential (2-4). Variable expression of actin, vimentin, CD68, BCL-2, desmin, and CD10 is commonly seen in UESLs (Figures 4A and B). Alpha-1-antitrypsin and alpha-1-antichymotrypsin positivity within the eosinophilic globules is commonly encountered (Figure 4C). (2-4, 7). Weak cytokeratin staining has also been reported, and a minority of UESLs have positivity for glypican 3 and nuclear positivity for CD117. As a result, glypican 3 should not be used on its own to rule out a hepatoblastoma and hepatocellular carcinoma. Rather glypican 3 should be deployed in a panel of stains and interpreted in conjunction with more reliable markers such as HepPARl and $\beta$-catenin. UESLs are usually negative for S100, MART1, myogenin, ALK-1, Beta-catenin, and HepParl $(2-4,7)$.

\section{ELECTRON MICROSCOPY}

Ultrastructually, USELs show electron-dense deposits in lysosomes and dilated rough endoplasmic reticulum. The lysosomal electron-dense deposits represent 

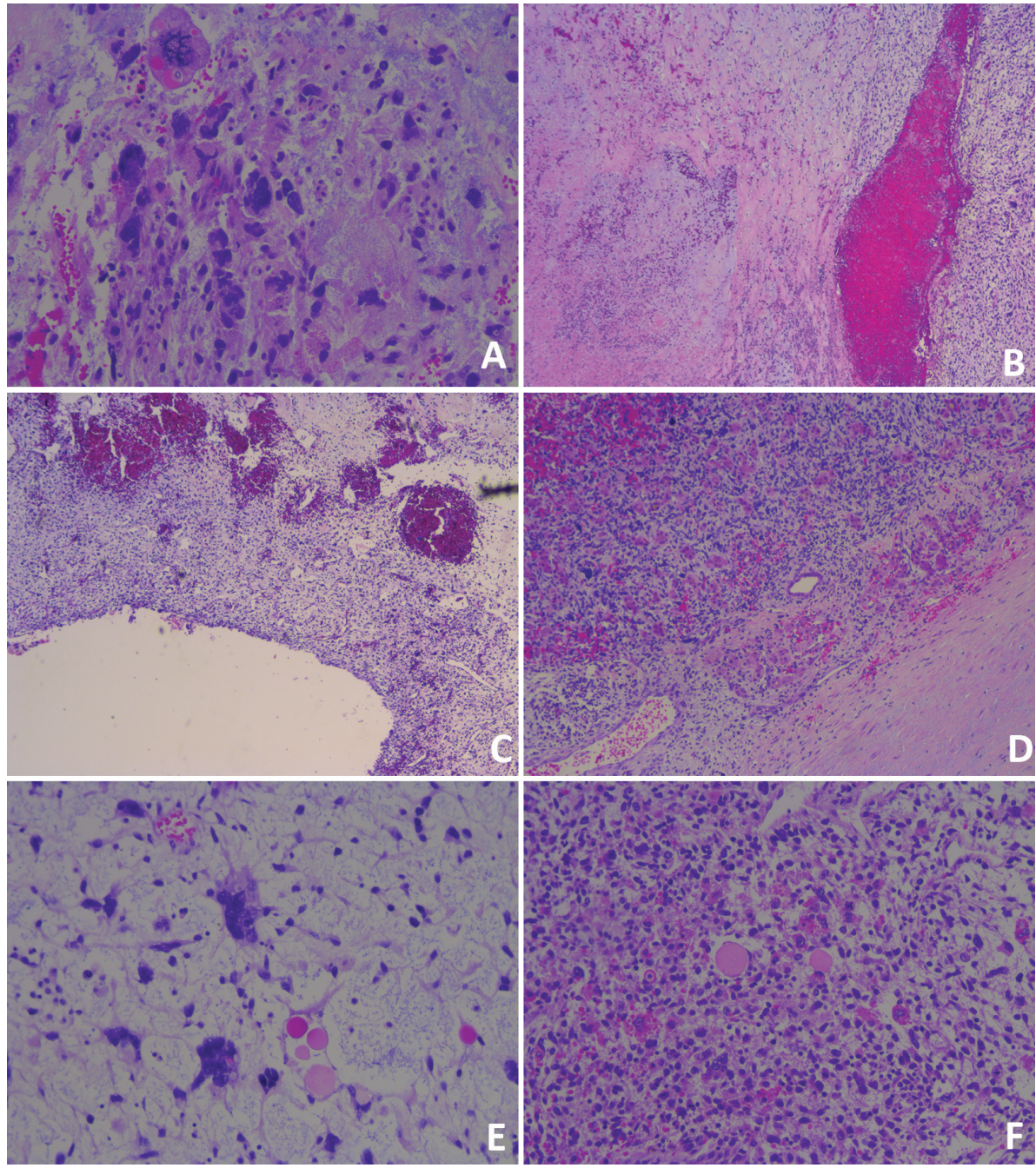

Figure 3. Histological features of undifferentiated embryonal sarcoma of the liver. A. High-grade myxomatous areas with considerable pleomorphism and an atypical mitotic figure.

B. Hemorrhagic area with abundant tumor necrosis. C. Hemorrhagic area with cystic change. D. Benign bile duct along with cords and nests of normal hepatocytes entrapped at the periphery of the tumor. Tumor pseudocapsule at the right bottom corner of the image. E. High-grade myxomatous area with PASD-resistant eosinophilic hyaline globules. F. Tumor cells with PASD-resistant eosinophilic hyaline globules.

the PASD-resistant eosinophilic globules seen histologically $(2,6,15,16)$. Some tumors in adults demonstrated myofilaments and intermediate filaments, suggesting smooth muscle differentiation (17). Lipoblastic differentiation has also been reported due to the presence of fat droplets $(2,15)$. 

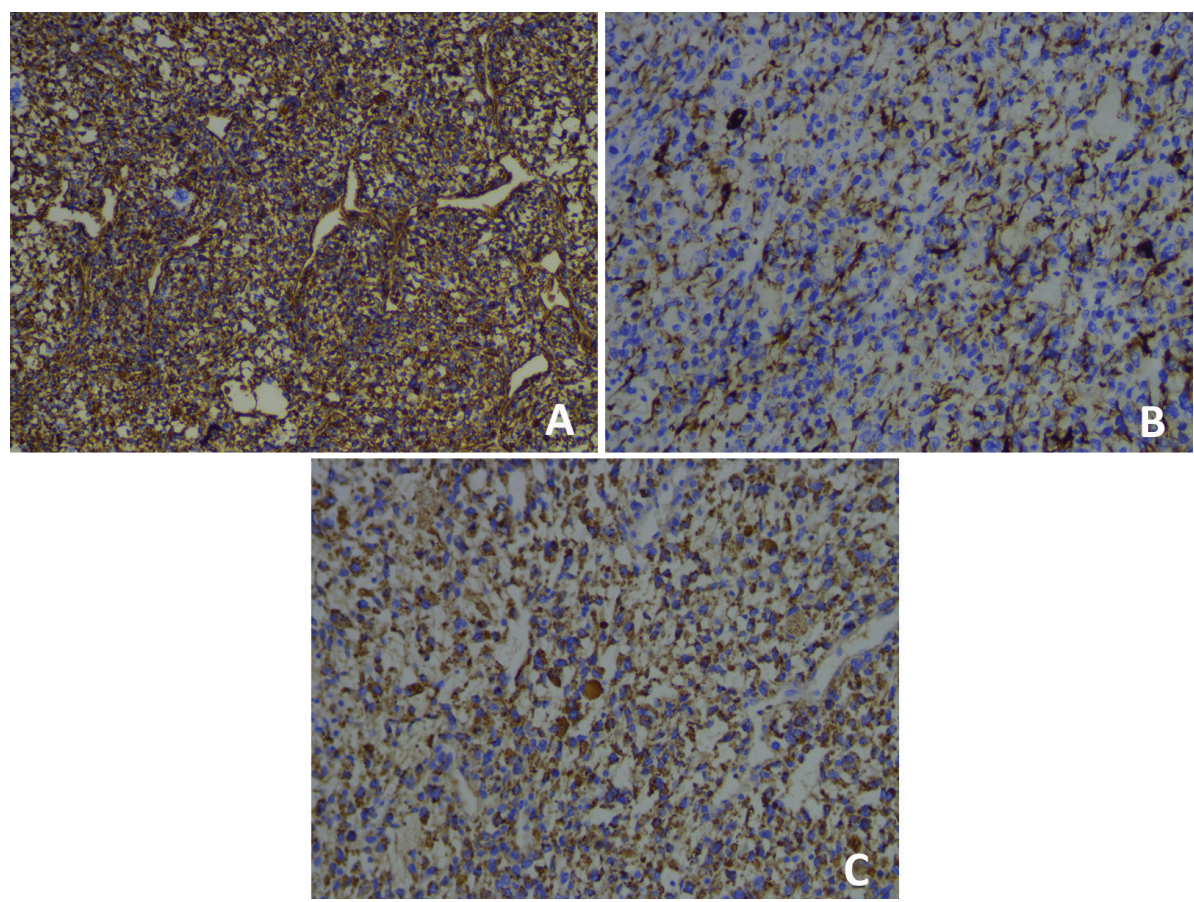

Figure 4. Immunohistochemistry (IHC) of undifferentiated embryonal sarcoma of the liver. A. Strong diffuse positivity for Vimentin IHC. B. Variable positivity for Desmin IHC. C. Positivity for Alpha 1-Antitrypsin IHC.

\section{MOLECULAR FINDINGS}

The pathogenesis of undifferentiated embryonal sarcoma of the liver is unclear. Molecular and cytogenetic aberrations found in some UESLs include alterations in p53 tumor suppressor gene leading to inactivation, and translocation $\mathrm{t}(11 ; 19)$ (q11;q13.3/13.4) and add(19)(q13.4). The break-apart site for the $\mathrm{t}(11 ; 19)$ was on the MALAT1 gene and this same translocation has been detected in some mesenchymal hamartomas. In addition, some undifferentiated embryonal sarcomas have areas that histologically resemble mesenchymal hamartomas which supports the belief that these two tumors are related. Areas that resemble mesenchymal hamartoma have also been reported in adult patients (18). As a result, it is believed that mesenchymal hamartomas could possibly be the precursor for some undifferentiated embryonal sarcomas $(2-4,10,19)$.

\section{PROGNOSIS AND TREATMENT}

UESL is predominately a pediatric tumor, and thus the literature about prognosis is predominantly based on data from pediatric patients. Historically, this tumor 
had an abysmal outlook before a multimodality treatment approach was instituted. Nowadays, the 5-year overall survival for children is around 86\% (1).

Surgical resection is the most important factor in the treatment of these patients. As with most tumors, the aim of such surgeries is to obtain negative margins although positive margins in some studies have not been shown to have considerable effect on outcome. This unexpected finding may be due to chemotherapy eradicating any residual tumor left. In addition, due to the rarity of this tumor, further data in the future will likely give a clearer picture concerning the impact of margin status (1).

Nowadays, chemotherapy is commonly used in combination with surgery in treating UESLs and this approach has been recognized as being a major factor in improving patient outcomes. The chemotherapy regimen used may vary between institutions and oncologists since a standardized approach has yet to be agreed upon $(1,4)$. In addition, a minority of patients had radiation treatment in the metastatic setting or in an attempt to prevent tumor recurrence. However, the effectiveness of radiotherapy is not clear at this time and more studies will be needed before a consensus can be reached (1). In patients with unresectable tumors, orthotopic liver transplant has been used and may be of benefit in certain situations. However, the data on orthotopic liver transplant as a treatment is limited $(1,3,4,10,20)$.

In summary, advances in surgery and the introduction of various chemotherapy regimens have been essential in achieving favorable outcomes for UESLs. These favorable outcomes currently apply to pediatric patients because there are not enough adult cases currently to make firm statistical conclusions. The rarity of this tumor means that there are still considerable limitations to our understanding of how to treat this tumor and further research in the future will be needed as more cases are accrued $(1,4)$.

\section{DIFFERENTIAL DIAGNOSIS}

Mesenchymal hamartoma is a benign mesenchymal liver tumor that predominately occurs within the first 5 years of life. This benign tumor has been known to occur in adults, but such cases are rare (21). The clinical presentation is usually an enlarging abdominal mass and depending on the size at presentation, the patient may have symptoms secondary to mass effect. Radiology usually shows a mass with solid and/or cystic features. Depending on the time of detection, the tumor can range considerably in size, with some cases reported measuring $30 \mathrm{~cm}$ (21). Pathology classically shows a bland myxoid background with cystic areas. Interspersed within this myxoid stromal element are blood vessels and bile ducts in a disorganized pattern. Islands or cords of normal appearing hepatocytes are usually present along the circumference of the tumor. Most cases will have areas of extramedullary hematopoiesis (21). Unlike a UESL, there are no worrisome histological features such as atypia, pleomorphism, atypical mitoses, or necrosis $(21,22)$. As mentioned earlier, mesenchymal hamartomas rarely undergo malignant degeneration into an UESL. There is considerable histological and molecular evidence that mesenchymal hamartomas and undifferentiated embryonal sarcomas are related and share certain pathways in their pathogenesis (21-23). 
Hepatoblastoma is a common differential (Table 1) especially in infants and children less than 5 years of age. Under the microscope, hepatoblastoma often looks like normal liver parenchyma in varying stages of embryonic development $(2,24)$. Although there are different histological subtypes of hepatoblastomas, many will have areas that resemble hepatocytes. In addition, most hepatoblastomas will not demonstrate the heterogeneous, myxoid, and/or pleomorphic

\section{TABLE 1 Differential diagnosis for undifferentiated embryonal sarcoma of the liver}

\begin{tabular}{|c|c|c|c|}
\hline Tumor type & $\begin{array}{l}\text { Clinical } \\
\text { Presentation }\end{array}$ & Histology & Ancillary Testing \\
\hline Hepatoblastoma & Children under 5 yo & $\begin{array}{l}\text { Usually resembles liver } \\
\text { parenchyma in various } \\
\text { stages of development. } \\
\text { Tend to have a more } \\
\text { uniform histology and } \\
\text { less heterogeneity than } \\
\text { UESL. }\end{array}$ & $\begin{array}{l}\text { HepPARl, glypican 3, } \\
\text { and } \beta \text {-catenin } \\
\text { positive. }\end{array}$ \\
\hline $\begin{array}{l}\text { Hepatocellular } \\
\text { carcinoma }\end{array}$ & $\begin{array}{l}\text { Mean age of pediatric } \\
\text { cases around } 11 \text { yo }\end{array}$ & $\begin{array}{l}\text { Malignant polygonal } \\
\text { hepatocytes in various } \\
\text { patterns histologically. } \\
\text { Mallory hyaline and } \\
\text { intracellular bile may be } \\
\text { present. Fibrolamellar } \\
\text { hepatocellular carcinoma } \\
\text { is also a common } \\
\text { subtype to be aware of. }\end{array}$ & $\begin{array}{l}\text { Keratins, glypican 3, } \\
\text { and HepPAR1 } \\
\text { positive. }\end{array}$ \\
\hline $\begin{array}{l}\text { Alveolar and } \\
\text { embryonal } \\
\text { rhabdomyosarcoma }\end{array}$ & $\begin{array}{l}\text { Pediatric or } \\
\text { adolescents }\end{array}$ & $\begin{array}{l}\text { Usually a small round blue } \\
\text { cell tumor. Certain } \\
\text { subtypes can appear } \\
\text { spindled or myxoid. }\end{array}$ & $\begin{array}{l}\text { Desmin, myogenin and } \\
\text { myoDl positive. } \\
\text { Most alveolar RMSs } \\
\text { will show PAX3- } \\
\text { FOXOl or PAX7- } \\
\text { FOXOl fusion. }\end{array}$ \\
\hline $\begin{array}{l}\text { Gastrointestinal } \\
\text { stromal tumors }\end{array}$ & $\begin{array}{l}\text { Most commonly in } \\
\text { adults (median } \\
\text { age } 65 \text { yo), but can } \\
\text { occur in children }\end{array}$ & $\begin{array}{l}\text { Most common is spindled } \\
\text { morphology in a } \\
\text { fascicular pattern but } \\
\text { can appear epithelioid or } \\
\text { mixed. }\end{array}$ & $\begin{array}{l}\text { DOGl, CD117 } \\
\text { positive. The vast } \\
\text { majority of GISTs } \\
\text { will also show c-kit, } \\
\text { PDGFRA, or SDH } \\
\text { mutations. }\end{array}$ \\
\hline Melanoma & $\begin{array}{l}\text { Most commonly in } \\
\text { adults. Very rare } \\
\text { to be a primary } \\
\text { liver tumor. }\end{array}$ & $\begin{array}{l}\text { Can have a variety of } \\
\text { histological appearances. } \\
\text { Spindled, epithelioid, or } \\
\text { even small round blue } \\
\text { cells. Some cases will } \\
\text { have melanin pigment in } \\
\text { the tumor cells, greatly } \\
\text { aiding in identification. }\end{array}$ & $\begin{array}{l}\text { S100, HMB45, } \\
\text { MART1, SOX10 } \\
\text { positive. }\end{array}$ \\
\hline
\end{tabular}




\section{TABLE 1 Differential diagnosis for undifferentiated embryonal sarcoma of the liver (Continued)}

\begin{tabular}{|c|c|c|c|}
\hline Tumor type & $\begin{array}{l}\text { Clinical } \\
\text { Presentation }\end{array}$ & Histology & Ancillary Testing \\
\hline $\begin{array}{l}\text { Perivascular } \\
\quad \text { epithelioid cell } \\
\text { tumor }\end{array}$ & $\begin{array}{l}\text { Usually in adult } \\
\text { patients }\end{array}$ & $\begin{array}{l}\text { Spindle to epithelioid cells } \\
\text { with prominent blood } \\
\text { vessels and sometimes } \\
\text { fat. }\end{array}$ & $\begin{array}{l}\text { HMB45, Actin, MART1 } \\
\text { positive. Less often } \\
\text { desmin and S100 } \\
\text { positive. }\end{array}$ \\
\hline Angiosarcoma & $\begin{array}{l}\text { Usually in older } \\
\text { adults }\end{array}$ & $\begin{array}{l}\text { Infiltrative atypical } \\
\text { spindle cells usually } \\
\text { with a vasoformative } \\
\text { architecture. }\end{array}$ & $\begin{array}{l}\text { CD31, CD34, ERG, } \\
\text { D240, Fli-1 } \\
\text { positive. }\end{array}$ \\
\hline Leiomyosarcoma & $\begin{array}{l}\text { Usually in older } \\
\text { adults }\end{array}$ & $\begin{array}{l}\text { Compact spindle cell } \\
\text { proliferation in a } \\
\text { fascicular pattern and } \\
\text { commonly with an } \\
\text { eosinophilic cytoplasm } \\
\text { reminiscent of normal } \\
\text { smooth muscle. } \\
\text { Depending on grade, } \\
\text { varying degrees of } \\
\text { cytological atypia, } \\
\text { mitotic activity, and/or } \\
\text { necrosis are present. }\end{array}$ & $\begin{array}{l}\text { Desmin, Actin, } \\
\text { Caldesmon } \\
\text { positive. }\end{array}$ \\
\hline $\begin{array}{l}\text { Undifferentiated } \\
\text { pleomorphic } \\
\text { sarcoma, } \\
\text { myxofibrosarcoma, } \\
\text { dedifferentiated } \\
\text { liposarcoma }\end{array}$ & $\begin{array}{l}\text { Predominately in } \\
\text { older adults. } \\
\text { These are soft } \\
\text { tissue sarcomas } \\
\text { that hardly ever } \\
\text { occur as a primary } \\
\text { liver tumor. }\end{array}$ & $\begin{array}{l}\text { High-grade pleomorphic } \\
\text { malignancy with } \\
\text { abundant mitotic activity } \\
\text { and necrosis. Variable } \\
\text { myxoid change present. }\end{array}$ & $\begin{array}{l}\text { Dedifferentiated } \\
\text { liposarcoma } \\
\text { is MDM2 IHC } \\
\text { positive and MDM2 } \\
\text { FISH amplified. } \\
\text { Correlation with } \\
\text { clinical-radiological } \\
\text { findings are } \\
\text { essential in ruling } \\
\text { out a metastasis } \\
\text { from a primary soft } \\
\text { tissue sarcoma. }\end{array}$ \\
\hline
\end{tabular}

histology seen in undifferentiated embryonal sarcomas of the liver. Also, some hepatoblastomas will have mesenchymal components with osteoid, chondroid, teratoid, or rhabdomyoblastic differentiation. The presence of these components would strongly argue against an undifferentiated embryonal sarcoma. Although immunohistochemistry may vary depending on the histological subtype, most hepatoblastomas are positive for HepPAR1, glypican 3, and $\beta$-catenin (2). In most cases, morphological features should allow for proper distinction from an UESL, but an immunohistochemical panel maybe necessary in ambiguous cases $(2,24)$.

Hepatocellular carcinoma (HCC) is the second most common primary malignant liver tumor in the pediatric age group, with hepatoblastoma taking the top spot (Table 1). A considerable number of these pediatric HCC patients will have 
predisposing factors such as alpha 1 antitrypsin deficiency, tyrosinemia, glycogen storage disorders, and chronic viral hepatitis (especially Hepatitis B). Most pediatric HCCs will morphologically resemble their adult counterparts (25). The fibrolamellar subtype of HCC is also commonly encountered, especially in young adults (26). The vast majority of HCCs in pediatric and adult patients will not have a sarcomatoid morphology (27) making histological distinction from UESL much easier. In addition, most HCCs will resemble hepatocytes to some degree and some HCCs will have Mallory hyaline and intracellular bile $(2,3)$. In addition, strong positive staining for glypican 3 and especially HepPARl should greatly assist in identifying an HCC in challenging cases $(2,3)$. As stated previously in the immunohistochemistry section, a minority of USELs will be positive for glypican 3 IHC.

Rhabdomyosarcoma is in the differential, especially in pediatric patients. Embryonal rhabdomyosarcomas tend to affect a young age group with around $60 \%$ of cases occurring before the age of $6(28,29)$. Alveolar rhabdomyosarcoma tends to have an older age onset, affecting children and adolescents with around half of cases occurring after 10 years of age $(28,29)$. A large portion of rhabdomyosarcomas will present as a small round blue cell tumor that has fairly uniform histology. A minority of cases will demonstrate anaplastic cellular features and show considerable nuclear pleomorphism. In addition, variants of embryonal rhabdomyosarcoma can have a myxoid background. In general, the vast majority of rhabdomyosarcomas will not demonstrate the histological heterogeneity of an undifferentiated embryonal sarcoma of the liver. Furthermore, rhabdomyosarcomas are strongly desmin-positive and will also be positive for one or both skeletal muscle markers (myogenin and MyoD1). An UESL may show variable desminpositivity but will not be positive for myogenin or MyoDl. In addition, the majority of alveolar rhabdomyosarcomas will have the PAX3-FOXO1 or PAX7-FOXO1 fusion which is not found in UESLs $(30,31)$.

Gastrointestinal stromal tumors (GISTs) most often occur in adults (32) and are usually easily identified because of their histology and positivity for CD117 and DOG1 IHC. GISTs primary to the liver are quite rare (33) when compared to their much more common counterparts in the digestive tract (28). Since GISTs have a well-known propensity to spread to the liver, most GISTs encountered on a liver biopsy will be a metastatic deposit $(34,35)$. Most cases of GIST will be the spindle cell type, composed histologically of a relatively uniform sheet of spindle cells. A minority of GISTs will be of the epithelioid cell type which can appear morphologically epithelioid, sclerosing, or sarcomatous. A minority of GISTs will be of the mixed type, meaning that epithelioid and spindle cells are both present within the same tumor $(34,36,37)$. Immunohistochemistry for CDl17 and DOGl will, in most cases, resolve any diagnostic dilemma $(2,38)$. Very rarely will a GIST be negative for both DOGl and CD117. Molecular testing for GIST mutations (c-kit, PDGFRA, SDH) may need to be undertaken in cases where GIST is still suspected but the IHC is non-contributory.

Melanoma is well known to be a great mimicker of any tumor histologically. Primary melanoma of the liver is quite rare, with metastatic melanoma being by far more common (39). When dealing with most sarcomatous appearing lesions, the differential should always include melanoma and the appropriate immunohistochemical stains should be done to exclude the possibility. S100 is a good stain to use when screening a sarcomatous lesion for the possibility of a 
melanoma (3, 40, 41). Additional follow-up stains such as SOX10, MART-1, MITF, and HMB45 are often used in conjunction with S100 in cases that need further workup. It should be noted that before diagnosing melanoma in the liver, one should always consider the possibility of a perivascular epithelioid cell tumor (PECOMA), because PECOMAs can also be positive for S100, MART1, MITF, and HMB45. As a result, appropriate myoid markers such as smooth muscle actin and desmin along with detailed examination of the histology should allow for proper distinction between a PECOMA and a melanoma $(42,43)$.

\section{OTHER SARCOMAS}

Myxofibrosarcoma or undifferentiated pleomorphic sarcoma (UPS) can have areas that closely resemble an undifferentiated embryonal sarcoma of the liver. However, myxofibrosarcomas and UPSs usually affect patients over 50 years of age and rarely occurs in children or young adults. In addition, the vast majority of these types of sarcomas occur in the soft tissue and do not present as a primary liver mass. Clinical presentation, age, past medical history of sarcomas, and adequate radiology are essential in ruling out a soft tissue sarcoma involving, extending, or metastasizing to the liver. Immunohistochemistry is of limited use in excluding a myxofibrosarcoma or UPS since these soft tissue sarcomas are usually negative for most immunohistochemistry and, like UESL, are diagnoses of exclusion (41).

Dedifferentiated liposarcomas are most commonly encountered as an intraabdominal/retroperitoneal mass. The histology can be quite varied, but an undifferentiated pleomorphic sarcoma-like morphology is considered the classic histology. Similar to UPS, this tumor usually presents in older adults and clinicalradiological investigations will often help to exclude this tumor as a diagnostic possibility. Dedifferentiated liposarcomas are MDM2 amplified and tests for MDM2 (that is, immunohistochemistry or fluorescent in situ hybridization) can be used in cases that require further work-up (44).

Angiosarcomas and epithelioid hemangioendotheliomas are rare mesenchymal tumors of the liver. Primary angiosarcomas of the liver usually occur in patients over 50 years of age while hemangioendotheliomas of the liver classically occurs in middle aged adults $(45,46)$. Most epithelioid hemangioendotheliomas (EHE) are easily recognized because of its myxochondroid matrix and the vacuolated endothelial cells arranged in nests or cords (2). Malignant variants of EHEs more closely resemble angiosarcomas and have high-grade infiltrative spindle cells that vaguely try to form vessels. Many angiosarcomas will show vasoformative areas and are not as pleomorphic or myxoid as an UESL, making the distinction easy. In difficult cases or on limited biopsy material, a panel of vascular markers (CD31, CD34, D2-40, ERG, and FLI-1) would be of considerable assistance (3).

Leiomyosarcomas are malignant tumors of smooth muscle. This tumor rarely occurs in the liver and the vast majority of primary liver cases happens in adults, mostly older adults. Most leiomyosarcomas in the liver will be a metastatic deposit from a primary elsewhere, so sufficient clinical-radiological information is essential. Leiomyosarcomas that are not high-grade are usually easily recognized histologically because of its close resemblance to normal smooth muscle. 
Higher-grade tumors can be more difficult to identify and, in such cases, immunohistochemistry will be necessary. Positivity for actin, desmin, and caldesmon is usually sufficient to rule out other possibilities in the differential $(3,47)$.

\section{CONCLUSION}

UESL is an aggressive malignancy that does occur in adults but is very rare. It presents clinically most often with non-specific symptoms of an abdominal mass with imaging features of a solid and cystic liver tumor. UESL is a diagnosis of exclusion in pathology, meaning that all other differentials must be reasonably excluded before a diagnosis of UESL can be confidently made. The pathogenesis and origin of UESL is unclear at this time, but molecular aberrations in p53 and translocation $\mathrm{t}(11 ; 19)$ have been found. In terms of treatment, considerable progress has been made by implementing a multimodality approach which has led to much more favorable outcomes for this high-grade liver tumor.

Acknowledgements: The author acknowledges Dr. Sarat Gaedde (Radiologist at the Cross Cancer Institute in Edmonton) in helping to provide and interpret the radiology images for this chapter.

Conflict of interest: The author declares no potential conflicts of interest with respect to research, authorship and/or publication of this chapter.

Copyright and permission statement: The author confirms that the materials included in this chapter do not violate copyright laws. Where relevant, appropriate permissions have been obtained from the original copyright holder(s), and all original sources have been appropriately acknowledged or referenced.

\section{REFERENCES}

1. Shi Y, Rojas Y, Zhang W, Beierle EA, Doski JJ, Goldfarb M, et al. Characteristics and outcomes in children with undifferentiated embryonal sarcoma of the liver: A report from the National Cancer Database. Pediatr Blood Cancer. 2017;64(4): e26272. https://doi.org/10.1002/pbc.26272

2. Putra J, Ornvold K. Undifferentiated embryonal sarcoma of the liver: a concise review. Arch Pathol Lab Med. 2015;139(2):269-73.

3. Pinamonti M, Vittone F, Ghiglione F, Borasi A, Silvestri S, Coverlizza S. Unexpected Liver Embryonal Sarcoma in the Adult: Diagnosis and Treatment. Case Rep Surg. 2018;2018:8362012. https://doi. org/10.1155/2018/8362012

4. Zhang H, Lei L, Zuppan CW, Raza AS. Undifferentiated embryonal sarcoma of the liver with an unusual presentation: case report and review of the literature. J Gastrointest Oncol. 2016;7(Suppl 1): S100-S6.

5. Gerson G, Valença JT, Cavalcante JM, Coêlho RDAB. Undifferentiated embryonal sarcoma of the liver in elderly: Case report and review of the literature. Indian J Pathol Microbiol.2019;62(1):129-31. https://doi.org/10.4103/IJPM.IJPM_508_16

6. Lee KH, Maratovich MN, Lee KB. Undifferentiated embryonal sarcoma of the liver in an adult patient. Clin Mol Hepatol. 2016;22(2):292-95. 
7. Silverberg, SG, Delellis RA, Sobin LH. Mesenchymal Tumors and Tumor-like Lesions. AFIP Atlas of Tumor Pathology Series 4: Tumors of the Liver. American Registry of Pathology, 2018. P. 313-28

8. Kallam A, Krishnamurthy J, Kozel J, Shonka N. Undifferentiated Embryonal Sarcoma of Liver. Rare Tumors. 2015;7(4):6009.

9. Kamrani K, Patel A, Guerrieri C, Bethel CAI, Phatak T. Undifferentiated embryonal sarcoma of the liver mimicking venolymphatic malformation. Radiol Case Rep. 2019;14(7):795-99.

10. Gao J, Fei L, Li S, Cui K, Zhang J, Yu F, et al. Undifferentiated embryonal sarcoma of the liver in a child: A case report and review of the literature. Oncol Lett. 2013;5(3):739-42. https://doi.org/10.3892/ ol.2012.1087

11. Hu MH, Zhang WL, Li J, Wen Y, Li F, Zhi T, Huang DS. Report of seven children with undifferentiated embryonal sarcoma of the liver. Chin Med J. 2019;132(18):2244-5. https://doi.org/10.1097/ CM9.0000000000000429

12. Te-Yu Hung 1, David Lu, Min-Chang Liu. Undifferentiated (embryonal) sarcoma of the liver complicated with rupture in a child. J Pediatr Hematol Oncol. 2007;29(1):63-65. https://doi.org/10.1097/ MPH.0b013e318030ac25

13. Chen JH, Lee CH, Wei CK, Chang SM, Yin, WY. Undifferentiated embryonal sarcoma of the liver with focal osteoid picture-A case report. Asian J Surg. 2013;36(4):174-8. https://doi.org/10.1016/j. asjsur.2012.06.012

14. Ishak KG, Goodman ZD, Stocker JT. Malignant Mesenchymal Tumors. In: Rosai J, Sobin LH. Atlas of Tumor Pathology: Tumors of the Liver and Intrahepatic Bile Ducts. Washington DC: Armed Forces Institute of Pathology, 2001. p. 313-230.

15. Agaram NP, Baren A, Antonescu CR. Pediatric and adult hepatic embryonal sarcoma: a comparative ultrastructural study with morphologic correlations. Ultrastruct Pathol. 2006;30(6):403-8. https:// doi.org/10.1080/01913120600854699

16. Keating S, Taylor GP. Undifferentiated (embryonal) sarcoma of the liver: Ultrastructural and immunohistochemical similarities with malignant fibrous histiocytoma. Hum Pathol. 1985;16(7):693-9. https://doi.org/10.1016/S0046-8177(85)80154-4

17. Nishio J, Iwasaki H, Sakashita N, Haraoka S, Isayama T, Naito M, et al. Undifferentiated (embryonal) sarcoma of the liver in middle-aged adults: smooth muscle differentiation determined by immunohistochemistry and electron microscopy. Hum Pathol. 2003;34(3):246-52.

18. Mori A, Fukase K, Masuda K, Sakata N, Mizuma M, Ohtsuka H, et al. A case of adult undifferentiated embryonal sarcoma of the liver successfully treated with right trisectionectomy: a case report. Surg Case Rep. 2017;3:19. https://doi.org/10.1186/s40792-017-0295-1

19. Hu X, Chen H, Jin M, Wang X, Lee J, Xu W, et al. Molecular cytogenetic characterization of undifferentiated embryonal sarcoma of the liver: a case report and literature review. Mol Cytogenet. 2012;5:26. https://doi.org/10.1186/1755-8166-5-26

20. Khan ZH, Ilyas K, Khan KH, Ghazanfar H, Hussain A, Inayat G, et al. Unresectable Undifferentiated Embryonal Sarcoma of the Liver in an Adult Male Treated with Chemotherapy and Orthotopic Liver Transplantation. Cureus. 2017;9(10): el759. https://doi.org/10.7759/cureus.1759

21. Siddiqui MA, McKenna BJ. Hepatic mesenchymal hamartoma: a short review. Arch Pathol Lab Med. 2006;130(10):1567-1569.

22. Patel RS, Misra V, Verma K, Gupta P, and Dhingra V. Benign Hepatic Mesenchymal Hamartoma (HMH) - A Case Report. J Clin Diagn Res. 2014;8(3):119-20. https://doi.org/10.7860/ JCDR/2014/6522.4129

23. Gupta R, Parelkar SV, and Sanghvi B. Mesenchymal hamartoma of the liver. Indian J Med Paediatr Oncol. 2009;30(4):14l-3.

24. Ranganthan S. Liver pathology. New York: Demos Medical; c2011. Chapter 28, Hepatoblastoma; p.411-56.

25. Khanna R, VermaSK. Pediatric hepatocellular carcinoma. WorldJ Gastroenterol. 2018;24(35):3980-99.

26. Lin CC, Yang HM. Fibrolamellar Carcinoma: A Concise Review. Arch Pathol Lab Med. 2018;142(9):1141-5.

27. Lee KB. Sarcomatoid hepatocellular carcinoma with mixed osteoclast-like giant cells and chondroid differentiation. Clin Mol Hepatol. 2014;20(3):313-6. 
28. Egas-Bejar D, Huh WW. Rhabdomyosarcoma in adolescent and young adult patients: current perspectives. Adolesc Health Med Ther. 2014;5:115-25.

29. Ognjanovic S, Linabery AM, Charbonneau B, Ross JA. Trends in Childhood Rhabdomyosarcoma Incidence and Survival in the United States (1975-2005). Cancer. 2009;115(18):4218-26.

30. Parham DM, Barr FG. Classification of Rhabdomyosarcoma and Its Molecular Basis. Adv Anat Pathol. 2013;20(6):387-97. https://doi.org/10.1097/PAP.0b013e3182a92d0d

31. Parham DM, Ellison DA. Rhabdomyosarcomas in Adults and Children: An Update. Arch Pathol Lab Med. 2006;130(10):1454-65.

32. Miettinen M, Lasota J. Gastrointestinal stromal tumors: review on morphology, molecular pathology, prognosis, and differential diagnosis. Arch Pathol Lab Med. 2006t;130(10):1466-78.

33. Nagai T, Ueda K, Hakoda H, Okata S, Nakata S, Taira T, et al. Primary gastrointestinal stromal tumor of the liver: a case report and review of the literature. Surg Case Rep. 2016;2(1):87. https://doi. org/10.1186/s40792-016-0218-6

34. Laurini JA, Carter JE. Gastrointestinal Stromal Tumors: A Review of the Literature. Arch Pathol Lab Med. 2010;134(1):134-41. https://doi.org/10.1038/labinvest.2010.17

35. Shi YN, Li Y, Wang LP, Wang ZH, Liang XB, Liang H, et al. Gastrointestinal stromal tumor (GIST) with liver metastases. Medicine (Baltimore). 2017;96(46): e8240. https://doi.org/10.1097/ MD.0000000000008240

36. Zhao X, Yue C. Gastrointestinal stromal tumor. J Gastrointest Oncol. 2012;3(3):189-208.

37. Lech G, Korcz W, Kowalczyk E, Guzel T, Radoch M, Krasnodębski IW. Giant gastrointestinal stromal tumour of rare sarcomatoid epithelioid subtype: Case study and literature review. World J Gastroenterol. 2015;21(11):3388-93.

38. Parab TM, DeRogatis MJ, Boaz AM, Grasso SA, Issack PS, Duarte DA, et al. Gastrointestinal stromal tumors: a comprehensive review. J Gastrointest Oncol. 2019;10(1):144-54.

39. Zhang Y, Hu Z, Wu W, Liu J, Hong D, Zhang C. Partial hepatectomy for primary hepatic melanoma: a report of two cases and review of the literature. World J Surg Oncol. 2014;12:362. https://doi. org/10.1186/1477-7819-12-362

40. Husain N, Verma N. Current Concepts in Pathology of Soft Tissue Sarcoma. Indian J Surg Oncol. 2011;2(4):302-8. https://doi.org/10.1007/s13193-012-0134-6

41. Goldblum JR. An approach to pleomorphic sarcomas: can we subclassify, and does it matter? Mod Pathol. 2014;27 Suppl 1:S39-46. https://doi.org/10.1038/modpathol.2013.174

42. Armah HB, Parwani AV. Perivascular epithelioid cell tumor. Arch Pathol Lab Med. 2009;133(4):648-654.

43. Uddin Z, Qureshi A, Fatima S, Kayani N. PEComa in a 12-year-old boy. BMJ Case Rep. 2010;2010: bcr04.2009.1735.

44. Matthyssens LE, Creytens D, Ceelen WP. Retroperitoneal Liposarcoma: Current Insights in Diagnosis and Treatment. Front Surg. 2015;2:4. https://doi.org/10.3389/fsurg.2015.00004

45. Huang IH, Wu YY, Huang TC, Chang WK, Chen JH. Statistics and outlook of primary hepatic angiosarcoma based on clinical stage. Oncol Lett. 2016;11(5):3218-22.

46. Sardaro A, Bardoscia L, Petruzzelli MF, Portaluri M. Epithelioid Hemangioendothelioma: An Overview and Update on a Rare Vascular Tumor. Oncol Rev. 2014;8(2):259. https://doi.org/10.4081/ oncol.2014.259

47. Shivathirthan N, Kita J, Iso Y, Hachiya H, KyungHwa P, Sawada T, et al. Primary hepatic leiomyosarcoma: Case report and literature review. World J Gastrointest Oncol. 2011;3(10):148-52. https://doi. org/10.4251/wjgo.v3.i10.148 